\title{
TENSIÓN HACIA DIOS Y EL SENTIDO SIMBÓLICO DE LOS NOMBRES DIVINOS EN DIONISIO AREOPAGITA
}

\author{
Gabriela de los Ángeles Caram* \\ doi: 10.11144/Javeriana.uph36-73.tdnd
}

\section{RESUMEN}

Los nombres divinos versa sobre los diversos nombres y expresiones metafóricas con que la Biblia denomina a Dios. Dionisio Areopagita desarrolla allí una teología "positiva", en tanto que argumentativa y explicitadora, utilizando el texto sagrado como fuente de conocimiento y verdad, en contraposición con la inexpresabilidad manifiesta de lo divino propia de una teología eminentemente apofática. En efecto, ante la inefabilidad de lo divino, el Areopagita se remite al estudio de los términos bíblicos y acuña los hápax, neologismos y vocablos con prefijo privativo, con el objeto de referirse de algún modo a lo sagrado. La presente investigación quiere mostrar que el objetivo del conocimiento de Dios en las reflexiones de Dionisio, a la vez que la comprensión del orden de las distintas esferas del ser -presente también en otras obras del Corpus Dionysiacum-, apunta a una unión con Él en una experiencia de hénosis y de vida en tensión permanente hacia lo Supremo. El artículo se enfoca en el estudio de las denominaciones de Dios, esto es, en una labor exegética de las diversas manifestaciones simbólicas que Dionisio acoge en su obra, con el propósito de aclarar el sentido de la eutonía o tensión hacia Dios presente en el pensamiento del teólogo bizantino.

Palabras clave: Dionisio Areopagita; nombres divinos; neoplatonismo; jerarquía universal

Universidad Nacional de Cuyo, Cuyo, Argentina.

Correo electrónico: gabycaram@hotmail.com

Para citar este artículo: Caram, G. A. (2019). Tensión hacia Dios y el sentido simbólico de los nombres divinos en Dionisio Areopagita. Universitas Philosophica, 36(73), 93-119. ISSN 01205323, ISSN en línea 2346-2426. doi: 10.11144/Javeriana.uph36-73.tdnd 


\title{
TENSION TOWARDS GOD AND THE SYMBOLIC MEANING OF THE DIVINE NAMES IN DIONYSIUS
}

\begin{abstract}
The Divine Names explores the different names and metaphoric expressions used in the Bible to refer to God. Dionysius the Areopagite is known as an exponent of positive theology, in the sense that he offers an argumentative and explicit account of the nature of God, relying on the Scripture as a source of knowledge and truth, in contrast to the declared inability of apophatic or negative theology to communicate any knowledge of the divine. Indeed, the Areopagite resorts to the study of biblical terms and to the coinage of hapax, neologisms often derived of known terms with added privative prefixes, in order to refer in some way to the sacred. Our research aims at showing that, for Dionysius, the purpose of pursuing the knowledge of God is not only to grasp the order of the different spheres of existence-present across the Corpus Dionysiacum - but also to connect with Him in hénosis, a living experience of permanent tension towards the Supreme. By focusing in the study of the names of God through exegesis, this paper aims at clarifying eutony, a constant tension towards God, as the central theme of the Byzantine theologian's thought.

Keywords: Dionysius the Areopagite; divine names; Neoplatonism; universal hierarchy
\end{abstract}




\section{Introducción}

Dionisio el Pseudo Areopagita, cuyo nombre verdadero es enteramente desconocido (Rolt, 2000, p. 4), fue un religioso posiblemente de origen sirio, quien desarrolló en la antigüedad tardía una elevada teología especulativa. La primera mención de "Dionysius" fue en el año 533, cuando Severo de Antioquía lo citó para sostener su postura ante el Concilio de Constantinopla (Stiglmayr, 1895, pp. 21-25). Fue extensamente leído por la Iglesia oriental y comentado ampliamente por Máximo Confesor en el siglo VII. Con la traducción de Scoto Eriúgena al latín, los escritos de este pensador entraron en la Iglesia de Occidente. Efectivamente ellos fueron recibidos con gran reverencia por la posteridad y citados en numerosos pasajes en la Opera omnia de Tomás de Aquino.

La mística de Dionisio alude al misterio, que es sombrío en su inefable incomprensibilidad, pero luminoso en cuanto es el camino de búsqueda de Dios en el seno de la creación. Esta no podría ser real si no estuviera sostenida por un amor, una gran tensión hacia lo absoluto, un anhelo de lo creatural por su creador ${ }^{1}$. Podemos recurrir al Sol, en un intento por ilustrar esta doble condición. Nuestra estrella anima la vida en la Tierra e ilumina las diferencias entre las diversas especies y los distintos cuerpos naturales, pero ella misma, y cualquier objeto que se le acerque, permanecen ocultos, de cierto modo, en su propio resplandor, por la incapacidad del ser humano de detener su visión en un objeto con tal potencia lumínica. Del mismo modo, la excelencia de Dios se oculta en lo inescrutable, escapando de la cognición humana, al tiempo que se manifiesta en el inmenso espectro de lo creado. El humano puede aspirar solo a una contemplación de la teofanía y siempre secuencialmente, no de manera

1 Se comprende que Dionisio presenta una doctrina creacionista, diferenciándose del neoplatonismo (Cavallero, 2007, p. 42). Esta idea se esclarece en el desenvolvimiento de un cierto vocabulario y en las reflexiones típicas de la tradición cristiana que se encuentran en el Corpus Dionysiacum, y en Los nombres divinos particularmente, tal como especifican con claridad Graciela Ritacco y Pablo Cavallero en el comentario filosófico y lingüístico desarrollado en la edición crítica de Los nombres divinos $(D N)$, a la que nos atendremos fundamentalmente en este trabajo. Se usará también la edición de Losada del 2008, que incluye un estudio filológico-lingüístico de Pablo Cavallero para las demás obras del Corpus: La jerarquía celestial $(C H)$, La jerarquía eclesiática $(E H)$, La teología mistica $(M T)$ y Epistolas (Ep.). En las referencias intertextuales se utilizará la abreviatura correspondiente a cada tratado, seguida de la numeración canónica. 
directa, sino por etapas, fragmentariamente. Como expresa Cícero Cunha Bezerra (2009): "el mundo es, por tanto, una theo-phania, una constante manifestación del Principio originario que, por su infinito amor por los hombres (philantropia), se muestra a través de símbolos y metáforas, luces y colores" (p. 18; traducción propia) $)^{2}$.

Por esta razón, Dionisio comprende que la teología es eminentemente negativa, como bien han descrito los estudiosos del Corpus Dionysiacum, quienes destacan que trasciende todo nombre y todo conocimiento. Sin embargo, la vía catafática ${ }^{3}$, o del ascenso en el conocimiento hacia la divinidad, es realizable en la medida en que nos podemos aproximar al Libro Sagrado y su verdad revelada, y que lo designa con diversos nombres, dando una idea comparativa de Dios, así como una cierta noción de sus perfecciones inteligibles.

Sus palabras iniciales nos conducen al propósito del tratado:

Ahora, oh bienaventurado, tras los Esbozos teológicos pasaré a la explicación de los nombres divinos, según sea accesible. Quede también predefinida por nosotros ahora la norma de los Oráculos en lo referente a que nosotros mostremos la verdad de lo dicho acerca de Dios, "no con persuasivas palabras de la sabiduría humana, sino con demostración del poderío", movido por el Espíritu, de los teólogos, [poderío] por el cual nos coligamos a lo impronunciable e ignoto, impronunciable e ignotamente, según la unión más fuerte que el poder y la actividad racional e intelectual en nosotros $(D N, \mathrm{I}, 1,107)$.

Los tres primeros capítulos de Los nombres divinos son introductorios, mientras que el resto trata acerca de los diversos nombres y expresiones metafóricas con que la Biblia denomina a Dios. Podría plantearse que la "demostración" que plantea Dionisio (I, 1) responde a una teología positiva, en tanto argumentativa y explicitadora, que utiliza el texto sagrado como modo de refrendar las afirmaciones, en contraposición con la inexpresabilidad manifiesta de lo divino de una

2 "O mundoé, portanto, uma the-phania, uma constante manifestação do Principio originario que, por seu infinito amor pelos homens (philantropia), mostra se através de simbolos e metáforas, luzes e cores".

3 La vía catafática de la teología admite la necesidad de comprender afirmativamente, de algún modo, lo inexpresable, la divinidad, a través de la exposición de los nombres de Dios. 
teología que se revela eminentemente apofática ${ }^{4}$ Y esto porque Dios es Aquel "que está sobre todo nombre", o el "sin nombre"; dicha inefabilidad lleva al Areopagita, por un lado, a estudiar los términos que aparecen en las Sagradas Escrituras, y por otro, a utilizar hápax ${ }^{5}$, neologismos y vocablos con prefijo privativo, con el objeto de referirse de algún modo a lo sagrado.

Esta investigación quiere mostrar que el objetivo del conocimiento de Dios, a la vez que la comprensión del orden de las distintas esferas del ser en las reflexiones de Dionisio, apuntan a la unión con Él en una experiencia de hénosis ${ }^{6} \mathrm{y}$ tensión permanente hacia lo Supremo, o eutonía.

4 Del verbo $\alpha \pi \circ \phi \dot{\alpha} \sigma \kappa \omega$, que significa 'negar'. La apófasis constituye una vía de conocimiento, el primer momento constitutivo de una experiencia que, en palabras de Bezerra (2007), "tiene como fundamento el 'abismo sin fondo' de la aphaíresis” (p. 120). Este último término es comprendido, según Vanneste (1958, p. 66) como una "acción de quitar", un "despojarse de". Aphaíresis, que en el Medioevo tendrá el sentido de ablatio, o abstractio (de Andía, 1996, pp. 379-382), en Dionisio adquiere el más hondo sentido de la "negación trascendente", que supera el plano de la discursividad del lenguaje para ascender a un estadio contemplativo, con una finalidad claramente espiritual o mística. Es así, entonces, que "la negación tiene un doble rostro: apófasis y aphaíresis. Mientras la primera corrige una afirmación, la segunda la supera o la trasciende” (Nieva, 2002, p. 216). Todo el camino de la vía negativa se encamina hacia la trascendencia de Dios; la mística de Dionisio se completa en la búsqueda de la Tiniebla divina.

5 Los hápax son los vocablos que aparecen solo una vez en Dionisio y solo en un texto del Corpus. De ellos al menos treinta y nueve son neologismos del autor.

6 La hénosis ( $\check{\nu} \nu \omega \sigma \varsigma)$ es la unión o unidad, idea que es básica en Dionisio y que se aleja del concepto neoplatónico de unidad divina. Su campo semántico está constituido por numerosos y variados vocablos que revelan una comprensión enmarcada en un texto filosófico y teológico que pretende esclarecer posiciones y distinguir tendencias en una época de intolerancia religiosa, reafirmando su ser cristiano $(D N, \mathrm{~V}, 7,185)$. Para un desarrollo más amplio véase de Andía, 1996: la autora define la hénosis según una amplia referencia y con una riqueza digna de ser trabajada en una investigación más extensa y completa. En sus palabras: «La unión es anagógica. Ella se produce en la superación del intelecto y la cesación de toda actividad ( $2 \nu \varepsilon v \varepsilon p \gamma \eta \sigma i \alpha)$ intelectual. Además, el desapego de lo que es y lo que no es (Dionisio advierte a Timoteo contra los no iniciados que permanecen apegados al ser y creen que no hay nada más allá de ser) y la supresión de cualquier actividad intelectual y de toda visión (Moisés se desprende de las cosas vistas y de ver antes de entrar en la oscuridad)

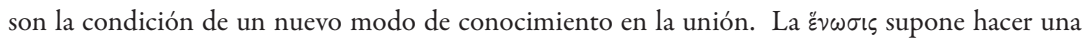
abstracción de los seres y cesar toda actividad noética, para ir más allá del ser y el intelecto: ella se realiza en su propia superación o en esa elevación hacia Dios o el Uno” (p. 425; traducción propia). [ « L'union est anagogique. Elle se fait dans le dépassement de l'intellect et la cessation de toute activité

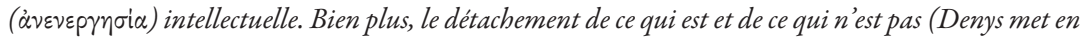
garde Timothée à l'égard des non-initiés qui restent collés aux étants et croiént qu'il n'y a rien au-delà 


\section{Los nombres de Dios}

\subsection{BREVE REFERENCLA AL CONTEXTO Y CONTENIDO $D E$ LOS NOMBRES DIVINOS}

LA RELACión ENTRE Dios y la CReACión será lo que fundamentalmente aporte el núcleo significativo del camino ascensional hacia Él. Elaborar una meditación acerca de sus Nombres puede ser el sendero de acceso hacia esta altísima Realidad. Como apunta Cícero Cunha Bezerra (2009):

Coincidiendo con Beierwaltes, afirmamos que el objetivo de la obra Los nombres divinos es establecer una investigación con bases filosóficas y bíblicas de los predicados divinos presentes en las hipótesis del diálogo platónico, a partir, naturalmente, de una perspectiva bien determinada y de una tradición asentada (p. 23; traducción propia). ${ }^{7}$

Bezerra menciona cuatro puntos tomados de Vogel (1993, p. 103) en los que el platonismo y el cristianismo coinciden, a saber: que las cosas visibles no constituyen una realidad primera; que la realidad finita expresa una realidad perfecta y absoluta, que la realidad invisible representa una realidad infinitamente superior a la sensible; que la realidad perfecta justifica y conduce la vida en general y al valor del ser humano en cuanto persona. A pesar de estos puntos comunes, hay ciertas especificidades que definen a Dionisio como un pensador original que integra el cristianismo a la cosmovisión neoplatónica.

Por su parte, Saffrey (1990, pp. 235-247) encuentra una deuda de Dionisio con la filosofía procleana y propone un lugar objetivo para este pensador dentro de la filosofía neoplatónica. Beierwaltes (1997) también encuentra impensable

de l'être) et la suppression de toute activité intellectuelle et de toute vision (Moïse se détache des choses vues et du voir avant d'entrer dans la ténèbre) sont la condition d'un nouveau mode de connaisance

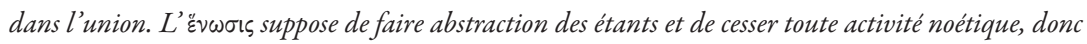
de dépasser l'être et l'intellect: elle se réalise dans ce dépassement même ou cette élévation vers Dieu ou $\left.L^{\prime} U n \gg\right]$.

7 "Coincidindo com Beierwaltes, afirmamos que o objetivo da obra Dos Nomes Divinos é establecer uma investigação com bases filosóficas e bíblicas dos predicados divinos presentes nas hipótesis do diálogo platónico, a partir, naturalmente, de uma perspectiva bem determinada e de uma tradição assentada”. 
una filosofía dionisiana sin el aporte procleano. Las ideas de las entidades mediadoras y de la unidad dinámica del cosmos sin duda constituyen un claro antecedente de la concepción jerárquica del pensador de Bizancio. Y en estos términos, el Areopagita edifica su pensamiento: "es evidente que, en Dionisio, los nombres divinos son equivalentes al binomio 'noetón-henádes', que comprende todo el ámbito complejo de la realidad que sigue al Uno, es decir, todos los atributos positivos con los cuales se clasifica la divinidad" (Corsini, 1962, p. 122, citado en Bezerra, 2009, p. 28; traducción propia) ${ }^{8}$. Sin embargo, Dionisio desarrolla con una eficacia y dinamismo nuevos la cuestión de la reciprocidad entre lo trascendente y los órdenes jerárquicos, lo cual es expresado como algo distinto de la necesidad lógica con que se despliega el cosmos de Proclo. Esta afirmación no pretende desvalorizar el sistema en el que cada orden participa del precedente necesariamente, sino que se concede mayor valor a la procesión dionisiana de los entes conforme al don divino de la gracia, un elemento completamente nuevo y revelador. En particular, la remisión a los nombres otorga una mirada viva acerca de Dios, que contempla tanto las semejanzas inteligibles como las comparaciones con el mundo sensible, revelando una enérgica y vital relación de todos los seres -en sus diferentes rangos- con Él. Dionisio tiene un objetivo muy específico, a saber: busca comprender la esencia de la realidad de Dios mediante un análisis filosófico y bíblico, desplegando de este modo un camino propio en la historia del neoplatonismo, que no puede prescindir de la creación como el paso de la unidad a la multiplicidad, y buscará siempre su bénosis o instancia unitiva con el Creador-Uno'. Es importante comprender que todos los principios neoplatónicos de los que se vale Dionisio sirven para fundamentar filosóficamente la unidad del pensamiento cristiano.

8 'é evidente que, em Dionísio, os nomes divinos são equivalentes ao binomio 'noetón-henádes', que compreende todo o âmbito complexo da realidade que segue o Uno, ou seja, todos os atributos positivos com os quais se classifica a Divindade".

9 Véase Bezerra, 2009: "la creación es lo que permite resolver el problema de la unidad y la multiplicidad, así como reabsorber, en relación con Dios, todos los caracteres de 'proodos' sin ceder a una confusión de carácter panteísta” (p. 31; traducción propia). [“a criação é o que permite resolver o problema da unidade e da multiplicidade, assim como, reabsorber, com relação a Deus, todos os caracteres da 'próodos' sem ceder a uma confusão de caráter panteistico"]. 
La capacidad de nombrar a Dios supone que podemos decir de Él todo y solamente aquello que nos han legado las Sagradas Escrituras. Estructuralmente, en todo conocimiento de Dios existe la impronta de la "creaturalidad"; por ello, es necesario remitirse a todo aquello que menciona el texto bíblico, referente siempre a lo creado. Desde el simbolismo que este nos ofrece, es posible ir avanzando ad extra hacia la divinización, como elevación y fuerza de atracción hacia Dios. De este modo:

En recta dirección, cuando sin entrar a sí misma ni moverse con intelectualidad inmediata -pues esto, como dije, es lo acorde a un círculo- sino avanzando hasta lo que está en torno a ella misma [el alma], es conducida, elevándose desde lo de fuera como desde unos símbolos diversificados y pluralizados, hasta las contemplaciones simples y unidas ( $D N$, IV, 9, 154).

Por esto, la negación absoluta en relación con el conocimiento de Dios no constituye la última palabra, como se tiende a ver en las especulaciones areopagíticas. Así, expresa Andereggen (1989): "es verdad que la vía negativa es más alta que la afirmativa, pues se adecúa a lo que Dios es en Sí, y la afirmativa lo alcanza solo parcial e imperfectamente" (p. 16). Según Dionisio, las negaciones son verdaderas en el ámbito de las realidades divinas, mientras que las afirmaciones no se adaptan a las realidades mistéricas; entonces el método de describir por medio de una teología simbólica parece ser el más conveniente al reino de lo invisible.

Sin duda, la posibilidad del conocimiento afirmativo ha sido dada por el mismo Dios, que ha fundado tanto este tipo de aproximación como así también la vía negativa, puesto que está allende todo conocimiento positivo o su contrario. Y esto se confirma en la Epístola IX de San Pablo (Ep. IX, 2 PG 3, 1108b, citada en Andereggen, 1989, p. 18), que expresa: "a partir del mundo creado, entendidas las obras, se comprenden las realidades invisibles de Dios, es decir su potencia y divinidad eternas".

El filólogo contemporáneo Pablo Adrián Cavallero, en su estudio preliminar de Los nombres divinos, señala que, en su estilo, el Areopagita utiliza un racionalismo expositivo contextualizado siempre por un lenguaje elevado y de tono místico. Esto es significativo toda vez que el bizantino escribe su texto durante el reinado de Justino I, quien había adoptado una postura ortodoxa frente a las 
herejías monofisitas ${ }^{10}$, maniqueas ${ }^{11}$ y montanistas ${ }^{12}$. En este sentido, el Corpus constituye una obra coincidente con la política del emperador y, aunque las controversias teológicas eran numerosas por esos tiempos, el pensador se muestra fiel a las disposiciones del Concilio de Calcedonia, y por ello sus exposiciones son claras y precisas en relación con el dogma reconocido:

En la Conferencia o Sínodo de Constantinopla del 533, en el que se cita el Corpus Dionysianum, todavía se discutían dudas acerca de la propiedad y corrección dogmática de este asunto. Debido a que en tal sínodo es un monofisita quien cita el Corpus, Severo de Antioquía, algunos creen que el autor del Corpus pertenecía al círculo monofisita. Pero en Dionisio aparecen las ideas clave referidas a la unión hipostática de Cristo, en la cual no había lugar para la confusión, la alteración, el cambio o la división (Cavallero, 2007, p. 23).

En algunos pasajes de Los nombres divinos, Dionisio combate específicamente el maniqueísmo $(D N, \mathrm{IV})$, al tiempo que se opone al pelagianismo, surgido hacia el 390, según el cual el hombre se bastaría a sí mismo sin el auxilio de la oración ni de la redención. Aparece además una referencia a la Virgen en $D N$, III, 2, 141 como "cuerpo principio de vida y receptáculo de la divinidad", aceptando el dogma de la recepción y concepción de lo divino por parte de la Virgen, pero también el ser fuente o principio de vida para Él, lo que confirma la doble naturaleza de Cristo.

En $D N$, I, 6, 118-119 se presenta a Dios según una extensa posibilidad de denominaciones, siempre sostenidas sobre la base escrituraria:

10 La postura monofisita sostiene que en Jesús hay una sola naturaleza, que es la divina, en contraposición con la que proclama Su doble naturaleza.

11 Maniqueísmo es la doctrina que considera que el mal es un coprincipio del Bien, la cual es combatida por el Areopagita en $D N$, IV, 18, 162 y ss.

12 El montanismo buscaba revalorizar ciertos elementos relativamente olvidados de la doctrina tradicional. Daba cuenta de una visión escatológica que afirmaba que el fin de los tiempos se acercaba y que llegaría en un plazo muy breve, con lo que resurgía la espera de la parusía tal como la habían esperado las primeras generaciones cristianas. Intentaron revivir el profetismo cristiano, que apenas existía en la época. Su concepción del profetismo difería sustancialmente de la tradición primitiva, puesto que los profetas del montanismo se consideraban receptáculos de la divinidad: no eran ellos quienes hablaban, era el Espíritu quien hablaba por su boca; Montano era un nuevo Paráclito que continuaba la revelación contenida en el Evangelio. 
"Yo soy el que es", "la vida," "la luz", "Dios", "la verdad", y cuando los mismos sabios en cosas de Dios cantan himnos al causante de todo con muchos nombres, a partir de todo lo causado, como bueno, como bello, como sabio, como amable, como Dios de dioses, como Señor de señores, como "Santo de santos", como eterno, como el que es y como causante de siglos, como corego de vida, como "sabiduría", como "inteligencia", como palabra, como conocedor, como el que provee todos los tesoros de todo conocimiento, como "potencia", como poderoso, como Rey de los reinantes, como antiguo de los días, como que no envejece e inmutable, como "salvación", como "justicia", como santificación, como redención, como el que está en grandeza sobre todo y como en aura sutil. Y también dicen que Él está en inteligencias y en almas y cuerpos y en cielo y tierra y a la vez Él mismo en sí mismo, intramundano, circamundano, supramundano, supracelestial, sol, astro, fuego, agua, espíritu, rocío, nube, piedra misma y roca, todos los entes mismos y ninguno de los entes $(D N, \mathrm{I}, 6)$.

Este espectacular detalle expresado por Dionisio es tan solo un fragmento de la alabanza que en su obra realiza a Dios, recordando todas aquellas formas finitas - pero infinitas a un tiempo- de nombrar al Supremo Ser.

El teólogo usa constantemente el término simbolos $(\sigma \dot{\sim} \mu \beta 0 \lambda \alpha)$ para referirse a las representaciones sensibles de Dios y de ángeles encontradas en las Escrituras y la liturgia. Tales símbolos, indica, son necesarios para los seres humanos, quienes deben ascender al intelecto desde la percepción sensorial ( $C H$, I, 3, 121c-124a). El símbolo es anagógico ${ }^{13}$, ya que implica un ascenso a lo superior y posee un papel educativo, pues es comprensible para nosotros.

Sobre esta base expone el contenido de los nombres divinos de la teología simbólica: por una parte, quedan expuestos los nombres inteligibles ${ }^{14}$ de Dios,

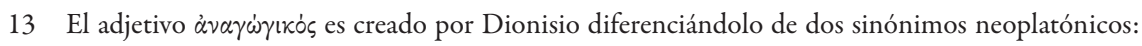

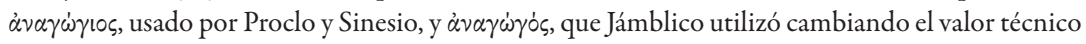
medicinal que tenía en Hipócrates, cuyo significado era "vomitivo". El adjetivo dionisiano tiene

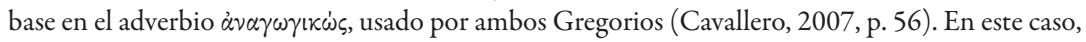
anagógico significa "que permite el ascenso a lo superior", "que conduce a lo superior".

14 Los nombres inteligibles son perfecciones inteligibles que el hombre descubre por abstracción intelectual en las criaturas y conoce a través de conceptos simples, que significan perfecciones puras. 
en cuanto se los conoce como perfecciones inteligibles que se encuentran en las escrituras, mientras que también se da lugar a los nombres en cuanto símbolos sensibles. Pero, así como el sentido y el intelecto no son opuestos, sino que permanecen en continuidad, los símbolos sensibles son continuos con los nombres inteligibles, y la distinción entre ellos queda relativizada ante la inconmensurabilidad de Dios, quien trasciende infinitamente a ambos. Un examen filosófico de la teoría de los símbolos de Dionisio muestra que incluso el nombre Ser es simbólico y que no puede darse un conocimiento no simbólico de Dios (Perl, 2007, p. 100).

Dado que todos los símbolos a los que se refiere Dionisio, en tanto nombres, se encuentran en las Escrituras, una explicación de su teoría del simbolismo podría parecer un estudio de su interpretación de estas, en lugar de un estudio del contenido específicamente filosófico de su pensamiento. Pero en la medida en que las expresiones de Dios que se encuentran en las escrituras incluyen expresamente todas las cosas, su exposición tanto de los nombres inteligibles como de los símbolos sensibles no es solamente una cuestión de exégesis bíblica, sino una descripción metafísica de la totalidad de los seres como teofanía o manifestación de Dios y, por lo tanto, también de todas las cosas sensibles como símbolos de Dios. Así, con respecto a la representación de Dios como luz, cita Romanos 1:20: "lo invisible [de Dios], como también su sempiterna potencia y divinidad, es visto, desde la creación del mundo, como inteligido en las creaturas" ( $D N, \mathrm{IV}, 4,149)$. Esto "invisible" se entiende de algún modo a partir de una teología simbólica.

En Los nombres divinos, además, explica cómo "los teólogos avanzan con completa continuidad por la serie de nombres asignados a Dios, como Ser, Vida y Bien, a una lista de nombres referentes a entes captables sensiblemente, como sol, estrella, fuego, agua, viento, rocío, nube, roca y piedra en sí, todos los entes y ninguno de los entes" ( $D N, \mathrm{I}, 6,119)$. El fundamento teórico de esta continuidad surge explícitamente en su relato en la Jerarquía celestial ( $\mathrm{CH})$ de representaciones "similares" y "disímiles" de Dios: "es doble el modo de la sagrada revelación: uno, avanzando como es natural mediante similares imágenes sacrofiguradas

Su contenido puede ser concebido como tal, sin limitación o restricción, y puede ser por consiguiente atribuido a Dios. Estas perfecciones son descubiertas como propias de Dios, en primer lugar, y, por derivación causal, de las criaturas, en carácter de dones o participaciones. 


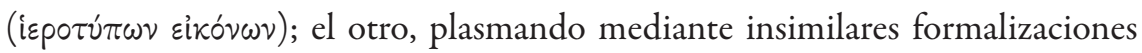
hasta lo totalmente inverosímil y desacorde" ( $\mathrm{CH}$, II, 2-3, 140c). Los símbolos "disímiles" son aquellos que parecen manifiestamente inapropiados en relación con los ángeles o Dios, como las bestias salvajes y las cosas inanimadas, mientras que los similares son aquellos que parecen más nobles y, por lo tanto, apropiados para lo que representan. Esta distinción es paralela hasta cierto punto a la relación entre representaciones sensibles e inteligibles. Sin embargo, Dionisio continúa explicando que la aparente conveniencia de los símbolos similares, incluyendo muchos de los nombres inteligibles, es, de hecho, una apariencia engañosa (Perl, 2007, p. 102). Así, dado que Dios no es ningún ser u objeto de pensamiento, es tan falso, en el mismo sentido, decir que Dios es Palabra, Mente o Ser, como decir que Él es león, piedra o fuego. Todas las expresiones inteligibles de Dios, no menos las sensibles, son finitas; en ese sentido, son igualmente inadecuadas y, por lo tanto, todas son diferentes de Él. Por esta razón, Dionisio dice incluso que las expresiones obviamente "diferentes" son, de hecho, más apropiadas, ya que indican más claramente la infinitud de todas las cosas de Dios: "si ciertamente las negaciones son verdaderas respecto de lo divino y las afirmaciones son inadecuadas para la ocultez de lo inexpresable, es mucho más apropiada, respecto de lo invisible, la revelación mediante disímiles plasmaciones" ( $\mathrm{CH}$, II, 3, 141a). Esa es la naturaleza del símbolo: transmitir, en el caso de los nombres divinos, lo semejante de lo desemejante.

Dado que todas las cosas existen solo al participar de las perfecciones de Dios, nada es absolutamente despreciado y nada es absolutamente inapropiado. Y ya que Dios es "todo en todo" y "nada en nada" (DN, VII, 3, 198), es tan verdadero decir que Él es león, piedra o fuego, como decir que es Palabra o Ser. Aquí Dionisio supera explícitamente cualquier distinción fundamental: todas las cosas, sean inteligibles o sensibles, son similares y diferentes, y esto es lo que significa ser un símbolo. Insistir en tal diferencia sería, una vez más, considerar a Dios no más allá del ser, sino como inteligible y finito, como objeto propio de algún modo de cognición. Todas las cosas, entonces, son en efecto símbolos de Dios, como sucede con los nombres. 


\subsection{LOS NOMBRES COMO ATAAMA Y SU LUGAR EN LA TEÚRGIA DIONISIANA}

\subsubsection{Los nombres como $\ddot{\alpha} \gamma \alpha \lambda \mu \alpha$}

LAS INVESTIGACIONES ACERCA DE LOS NOMBRES DIVINOS se presentan como divergentes del tratamiento de las palabras que nombran a las cosas. Pseudo Dionisio incluye en su teoría un uso no referencial de los nombres divinos, esto es, un modo distinto de relacionar la denominación con la cosa. Siguiendo a Naomi Janowitz (1991), leemos este pasaje: "Pseudo Dionisio llama a los nombres divinos 'estatuas': un modo muy diferente de explicar cómo los nombres divinos representan la deidad en la Tierra. [...] Los nombres divinos no son completamente arbitrarios, y las palabras se pueden emplear en transformaciones rituales" (p. 360; traducción propia) ${ }^{15}$. En su pronunciamiento gozan de la capacidad de conversión; cada uno de ellos posee un poder transformador que une y diviniza, gracias a su poder unificador, según el cual conducen de la multiplicidad polisémica (la diferencia) hacia la simplicidad absoluta. Es Dios quien, en su infinita bondad, acepta desvelarse mediante símbolos e imágenes. En el sistema de procesiones cósmicas a partir de Dios, no pueden ser arbitrarios o carentes de significación. Si el tratado dionisiano es tan importante es porque, entre otras cosas, ayuda a resolver el problema cosmológico de cómo concebir la relación entre el más alto nivel de realidad, el absolutamente trascendente, y el último nivel óntico: el mundo de la materia. Para poder apreciar la dimensión cristológica del universo dionisiano, debemos recordar la definición de jerarquí, una palabra que utiliza para caracterizar el ordenamiento sin fisuras que existe en los cielos, en la Tierra y en la Iglesia, valorando cada nivel del ser. La jerarquía se presenta como un "sagrado orden, ciencia y actividad asimilados a lo deiforme". Y continúa: "ciertamente el objetivo del sagrado gobierno es la asimilación a Dios" (CH, III, 1-2, 164d-165a). Asimilación y unión constituyen la deificación, que, a su vez, constituye el propósito de los tratados dionisianos.

15 “Pseudo Dionysius calls divine names 'statues': a very distinct means of explaining how divine names represent the deity on Earth. [...] Divine names are not completely arbitrary, and words can be used in ritual transformations." 
A través del nombramiento de Dios es posible el ascenso hacia la unidad con Él. Janowitz (1991), además, expone:

A medida que leemos el tratado del Pseudo-Dionisio, que explica un nombre después de otro, no debemos captar el contenido de cada nombre que estudia, sino la conexión entre el nombre divino y la divinidad nombrada. La más peculiar descripción que concreta este punto es la afirmación de Pseudo-Dionisio de que los nombres divinos son "estatuas" (p. 367; traducción propia). ${ }^{16}$

El sentido de este peculiar término, estatuas, constituye la condición de posibilidad de la conexión entre el nombre divino y la divinidad que es nombrada. Aparece también al comienzo del capítulo nueve de Los nombres divinos: puesto que también lo grande y lo pequeño han sido referidos al causante de todo, y lo idéntico y lo diferente, y lo similar y lo disímil, y la estabilidad y el movimiento, ¡vamos!, contemplemos también cuantas cosas de estas estatuas relativas a la divina denominación nos son manifiestas ( $D N$, IX, 1, 207; cursivas añadidas).

El término estatuas se deriva de $\ddot{\alpha} \gamma \alpha \lambda \mu \alpha^{17}$, que significa 'ofrenda' o 'estatua', pero especialmente en honor a los dioses, o en el sentido más general de 'retrato' o 'imagen', y que también se traduce como 'gloria,' 'gozo' u 'honor. ${ }^{18}$ Dionisio toma la noción de los griegos, que a la vez que conciben estas imágenes como externamente desvalorizadas, admiten que internamente contendrían la belleza de los dioses, del mismo modo que ocurre con las denominaciones mencionadas en las Sagradas Escrituras. Serían como "estatuas dotadas de voz", al decir de Damascio" ${ }^{19}$ o como

16 "As we read throughout Pseudo-Dionysius's treatise, which explains one name after another, we must grasp not the particular content of each name he discusses, but instead the connection between divine name and divinity named. The most idiosyncratic description which concretizes this point is PseudoDionysius's statement that divine names are 'statues."

17 Según van den Daele (1941), agalma ( $\alpha \gamma \alpha \lambda \mu \alpha)$ aparece algunas veces en el corpus dionisiano: $D N$, IX, 1; $C H$, II, 5; $C H$, III, 2; $E H$, III, 3; $E H$, IV, 1, 473a; $E H$, IV, 1, 476a; $M T$, II.

18 Véase Pantelia, 2011, p. 5.

19 En el Comentario al Filebo, Damascio refiere que un tal Demócrito llamó a los nombres divinos "estatuas dotadas de voz" (Cavallero, 2007, pp. 325-326, n. 1). 
aparece en Teología platónica (I, 29) de Proclo ${ }^{20}$, en donde las "estatuas" demuestran la presencia de dioses del mismo modo que los nombres divinos expresan su naturaleza y los hacen presentes intelectualmente ${ }^{21}$. Por eso se habla del simbolismo dionisiano. En palabras de Wear y Dillon (2007):

Tanto Dionisio como Proclo trazan una conexión entre los nombres y las estatuas. Proclo identifica los nombres divinos con el uso ritual de las estatuas como refugio de los dioses. Al dibujar esta analogía, enfatiza su papel como símbolos teúrgicos. Dionisio continúa con esta tradición: los "símbolos sagrados" [symbola] son, en efecto, imágenes perceptibles (agalmata) de "realidades inteligibles" y "debemos examinar todo lo que se nos manifiesta a partir de estos agalmata que son los nombres divinos". Para Dionisio, son las imágenes que deben ser trascendidas por aquellos que desean ver los tipos verdaderos, y la jerarquía hace que sus miembros sean imágenes divinas (p. 94; traducción propia).22

20 En relación con esta noción en el pensamiento de Proclo, citamos de Saffrey y Westerink (1968): "en resumen, por lo tanto, se debe admitir que los primeros, los más principales y verdaderamente divinos nombres están establecidos en los mismos dioses. Pero hay que decir que los nombres secundarios, que son imitaciones de los primeros y que subsisten intelectualmente, son de una asignación demoníaca. Y, de nuevo, podemos decir que aquellos nombres están en tercer lugar a partir de la verdad, que están diseñados lógicamente y que reciben la última semejanza de las naturalezas divinas, son revelados por los practicantes adiestrados, actuando ahora bajo la inspiración divina, ahora intelectualmente y generando imágenes en movimiento de sus visiones internas" (p. 124; traducción propia). ["in short, therefore, it must be admitted that the first, most principal and truly divine names are established in the gods themselves. But it must be said that the secondary names, which are imitations of the first and which subsist intellectually, are of a daemonic allotment. And again, we may say that those names which are third from the truth, which are logically devised and which receive the ultimate resemblance of divine natures, are revealed by skilled practitioners, acting now under divine inspiration, now intellectually, and generating moving images of their inward visions."]

21 Se considera que los neoplatónicos desarrollaron la teoría de los nombres divinos desde comienzos del siglo $\mathrm{V}$ como sustitutos de las estatuas que, por decretos imperiales debieron ser eliminadas de los templos. Véase Cavallero, 2007, p. 326, n. 1.

22 "both Dionysius and Proclus draw a connection between names and statues. Proclus identifies the divine names with the ritual use of statues as harbourers of the gods. In drawing this analogy, he emphasizes their role as theurgic symbols. Dionysius continues this tradition: the 'sacred symbols' [symbola] are actually the perceptible images (agalmata) of 'intelligible realities' and 'we must examine all that is manifested to us from these agalmata that are the divine names.' For Dionysius, they are the images 
Según había expresado Proclo en la Teología platónica, el nombre genera algo similar a una estatua del dios. Señala que, a medida que el arte teúrgico invoca a través de ciertos símbolos la bondad de los dioses en la iluminación de estatuas artificiales, así también la ciencia intelectual de los asuntos divinos, en la composición y división de los sonidos, despliega la esencia oculta de los dioses. Es necesario venerar hasta los últimos ecos del dios para corresponder con las entidades divinas (Proclo, citado en Saffrey \& Westerink, 1968, p. 124).

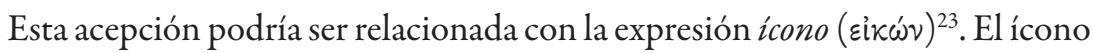
permite la comprensión que la antigüedad tardía asigna a los nombres divinos como palabras no arbitrarias referidas a la divinidad, y que encarna en su forma un poder celestial (Janowitz, 1991, p. 371). En el caso de Dionisio, se trataría más bien de relacionar $\alpha$ $\gamma \alpha \lambda \mu \alpha$ con los símbolos, pues un símbolo -según la teoría de Peirce- es un signo que perdería el carácter de tal si no tuviera un intérprete que pueda comprender su significación (Peirce, 1932, 2, 274)24. Los nombres aparecen de este modo como símbolos o específicas manifestaciones del poder divino sobre la tierra y, en este trascendental sentido, el lenguaje cumpliría el rol de teúrgia. Así es que la exégesis escritural dionisiana no se propone como meramente alegórica, sino que ciertamente estos símbolos teúrgicos significan la más alta realidad (Wear \& Dillon, 2007, p. 86).

\subsubsection{Caracteres de la teúrgia en general y de la teúrgia dionisiana}

Según explicita Charles M. Stang (2010, p. 185), la teúrgia en cuanto obra de Dios ( $\theta_{\text {coupria }}$ ) experimentó un importante desplazamiento entre su vinculación originaria en el seno del paganismo con los Oráculos caldeos ${ }^{25}$ y sus

that must be transcended by those wishing to see the true types, and the hierarchy causes its members to be divine images."

23 El término ícono procede de $\varepsilon i k \omega ́ v$, que, según el diccionario LSJ (Pantelia, 2011, p. 485), significa 'imagen', 'representación', e incluso 'arquetipo'.

24 Como corresponde a la citación habitual de Collected Papers of Charles Sanders Peirce, aquí se coloca volumen y parágrafo.

25 Las tres primeras atestiguaciones de la voz $\theta$ covp $\gamma$ - comparten dos rasgos importantes: tienen lugar en fuentes contemporáneas que datan aproximadamente de la segunda mitad del siglo II d. C. y, 
supuestos autores, conocidos como julianos, hasta la mística cristiana del Areopagita.

La recepción neoplatónica de la teúrgia comenzó con Porfirio (circa 234305 d. C.) y llegó a Damascio (circa 480-550 d. C.), el último diadochus de la Academia de Atenas. A Porfirio generalmente se lo considera como el gran escéptico de la teúrgia; siguiendo a Plotino, la estima como algo parecido o peor que la magia. Según Georg Luck (1989, p. 209), Porfirio no se muestra claro con respecto a la teúrgia, ya que nunca la rechazó abiertamente, pero tampoco confía en su eficacia. San Agustín critica la ambigüedad porfiriana, ya que vacila en interpretarla o bien como superstición, o desde el punto de vista filosófico. Sin embargo, elogia a Porfirio por su Carta a Anebo, en la que el filósofo describe la teúrgia como un medio para obligar a los dioses (demonios o ángeles caídos, entiende Agustín) a llevar a cabo algún fin determinado. Por medio del conocimiento -aunque fragmentario- de esta carta, y gracias a San Agustín, sabemos que los teúrgos creían poder obligar a los dioses a cumplir su voluntad, cosa que repugnaba a Porfirio y que parecía la característica de esta práctica en el siglo III. La mencionada Carta de Porfirio condujo a su seguidor Jámblico de Calcis (circa 250-330 d. C.) a escribir Sobre los misterios de los egipcios, de los caldeos y de los asirios ${ }^{26}$, una obra maestra acerca de la teoría teúrgica, con una interesante interpretación mística (Stang, 2010, p. 191). Señala Álvaro Fernández Fernández (2011) en su formidable texto La teúrgia de los Oráculos caldeos:

La conexión entre la teología y la teúrgia se documenta por vez primera en el De mysteriis de Jámblico. No está claro si fue Porfirio quien apuntó previamente este vínculo en la Carta a Anebo. Ambos conceptos, por otro lado, se complementan con henchida claridad en la Jerarquía eclesiástica

por otra parte, en ellas se menciona a los $\theta$ rovproi (nombre sustantivo, común y plural que refiere a los teúrgos, quizás como una agrupación de individuos) y no propiamente la $\theta$ coupyi $\alpha$. Los documentos mencionados son los Oráculos caldeos, atribuidos a los julianos, el Onomastikon de

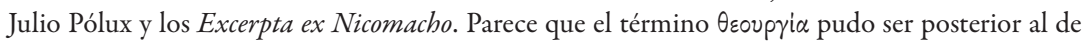
$\theta$ Eovpyoi, por lo que sería un sustantivo derivado de él, y que debió surgir a finales del siglo III para dar nombre al tipo de actividad peculiar que ya venían desempeñando los teúrgos desde un tiempo atrás (Fernández Fernández, 2011, pp. 312-313).

26 Sobre las características del pensamiento de Jámblico se puede consultar Molina Ayala, 2010. 


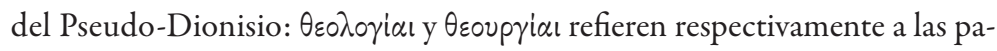

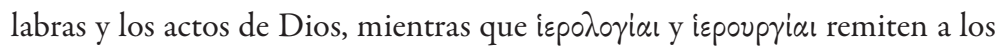
dichos y las obras de los hombres que son santos (p. 324).

La teúrgia de los nombres para el Areopagita es un momento catafático en el que la obra divina se manifiesta y que, a su vez, conduce hacia el despliegue de la fase apofática. La primera corresponde a un momento de salida de sí y procesión de lo divino en el cosmos, el éxtasis divino. La apóphasis articula y promueve el movimiento de regreso del alma más allá de sí, hacia la trascendencia divina, generando el éxtasis de la criatura. El objetivo de la teúrgia, a través del símbolo de los nombres divinos, es el encuentro del hombre con Dios, en vistas a la consumación inefable de la unión (bénosis) en que la criatura se abandona a sí misma en Dios, que está más allá del ser. De este modo, el éxtasis divino, que llama a ser a todas las criaturas, y el éxtasis humano, que responde a dicha llamada, son uno. No para que el humano sea Dios, sino para permanecer con Él.

Es importante aclarar que gran parte de la ambigüedad de la idea de teúrgia se debe a que se la ha comprendido, a grandes rasgos, de dos maneras diferentes, según sostiene Charles Stang (2010):

Si "teúrgia" ( $\theta_{\text {coup }}$ i $\alpha$ ) procede de un sintagma con un genitivo "la obra de

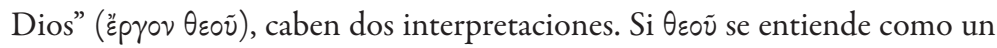
genitivo objetivo, entonces la teúrgia es la obra que el teúrgo realiza de cara a los dioses, esto es, influyendo sobre ellos o incluso obligándolos a hacer lo que él desee. Si $\theta$ roũ se entiende como genitivo subjetivo, la teúrgia es, entonces, la obra que ejecutan los propios dioses, presumiblemente en y a través del teúrgo, en cuyo caso se convierte en una especie de vehículo para la acción divina (p. 189).

El Areopagita transformó el significado de la teúrgia del genitivo objetivo de los Oráculos caldeos y Jámblico (como una obra dirigida a los dioses con finalidad salvífica) en la acepción del genitivo subjetivo, que alude a la obra divina mis$\mathrm{ma}$ (Rorem, 1984). La primera mención de la teúrgia está en la Jerarquía celeste ( $\mathrm{CH}, \mathrm{IV}, 4,181 \mathrm{~b})$, con la "teúrgia de Jesús", lo cual deja claro que la obra divina por excelencia es la Encarnación de Jesús, como teúrgia humana, en la que Dios, mientras estuvo encarnado, realizó obras divinas. 
La teúrgia en Dionisio se presenta como una actividad infinitamente superior -en algún sentido, en cuanto conecta con lo más elevado- a lo que se denomina rito, o una acción relacionada con lo divino. La teúrgia es la aproximación hacia lo divino, a partir de ciertas celebraciones sublimes, propiamente sacramentales, a la vez que al nombrar su Ser, que, más que una práctica religiosa de invocación de poderes supraterrenos ${ }^{27}$, es la comunicación misma con el Magnánimo, con el Señor de los tiempos; dispone hacia la hénosis más perfecta de nuestra realidad con el Supremo, unidad que está sostenida por Él mismo, legándonos los elementos necesarios para alcanzarlo, aun en medio de nuestra imperfección natural.

En Los nombres divinos, dicha bénosis se realiza a partir de las nominaciones escriturarias, que tienden un camino - no directo- que va de las criaturas hacia la divina Tearquía. Para avanzar en este camino, se parte del símbolo, que nos eleva hasta la unidad de la deificación. Pero para ello, es necesario recorrer un camino de purificación que conlleva la supresión de todo lo que es contrario a Dios, para dar forma a las disposiciones del alma de modo que ella reciba lo mejor posible las palabras sagradas $(E H$, II). Solo un alma purificada puede contemplar y conocer aquello que trasciende toda imagen y todo conocimiento. En Apóphasis y kénosis en Dionisio Pseudo Areopagita, apunta Bezerra (2007):

En Los nombres divinos, Dionisio subraya la necesidad de valernos de símbolos para entender, en la medida de lo posible, las realidades divinas, pero, en seguida, hay que abandonarlos, despojarse de todo entender y elevarse hasta el silencio más profundo. Estamos refiriéndonos, por tanto, a avanzar de negación en negación a la "Tiniebla” que está más allá de toda negación (p. 120).

\subsection{LA INEFABILIDAD DE DIOS Y SUS EXPRESIONES COMO HÁPAX}

EN UN PROCESO MÁS AVANZADO DE EXÉGESIS, para poder entender el proceso de revelación divina mediante sus nominaciones, el primer paso consiste en comprender la relación entre la identidad y la diferencia, en cuanto constituyentes de

27 Dionisio no considera las prácticas antes usadas características de la teúrgia más antigua como la animación de estatuas, la conjura de los dioses a través de un médium, el uso de piedras o de amuletos apotropaicos, entre otros. 
una unidad dinámica que tiene al propio Dios como su fundamento, de manera que Dios garantiza la unidad de lenguaje y ser.

El bizantino utiliza un lenguaje muy particular para desplegar la cuestión principal de su tratado; él se esfuerza por articular lo indecible, y en este menester encuentra muy pronto un obstáculo que le impide dar con la comprensión más cabal y acertada de Dios. Cavallero lo manifiesta de este modo:

Con todo esto Dionisio está diciendo que Dios supera en dignidad y en esencia cualquier cosa que pueda recibir su nombre, pero a la vez indica que el Hombre, en su intento de alabar y a la vez acercarse a su Dios, se esfuerza por expresar, según sus débiles fuerzas, lo inexpresable, guiado siempre por la misma revelación divina. Y él mismo, más allá de hurgar en las imágenes aplicadas a Dios por la Sagrada Biblia, fuerza su propio léxico para plasmar poéticamente esa tensión hacia lo imposible. ¿Cómo forja Dionisio su léxico para expresar lo inexpresable? ¿Qué ideas rectoras caracterizan la inefabilidad de Dios? (Cavallero, 2007, p. 29)

La concepción dionisiana sirve a fines semiótico-epistemológicos, antes que ontológicos, puesto que no pretende modificar la realidad, sino aproximarnos al abismo de Grandeza por la vía del conocimiento. Su clara intención es procurar alcanzarlo desde la pequeñez de las facultades humanas, en un esfuerzo tensional hacia las tinieblas de lo supremo. Dios excede todo principio de carácter semántico, pero a causa de su infinita bondad, no hay intentos vanos en la búsqueda de Dios. En su nombramiento también nace el deseo de unidad con Aquél y un intento de comprensión de su Ser. Dionisio explica:

Acerca de estas cosas es necesario buscar cómo nosotros conocemos a Dios, que no es ni inteligible ni sensible ni es por entero ninguno de los entes. En efecto, ¿̇acaso no es verdadero decir que no conocemos a Dios a partir de su naturaleza -pues esto es incognoscible y supera toda razón e inteligenciasino que, a partir de la disposición de todos los entes, como proyectada a partir de Él, y teniendo algunas imágenes y semejanzas de sus divinos paradigmas, hacia lo más allá de todo subimos por camino y orden, según es posible, en la supresión y supraeminencia de todo y en la causa de todo. Por ello no solo Dios es conocido en todas las cosas, sino también fuera de todo. [...] Y propio de Él es intelección y razón y ciencia y tacto y sensibilidad y opinión e 
imaginación y nombre y todo lo demás, pero ni es inteligido ni es dicho ni es nombrado (DN, VII, 3, 197-198).

No es ninguno de los entes, pero tampoco puede ser conocido en su esencia; por eso dice que es "todo en todo" y "nada en nada" (VII, 3, 198). De modo que el propósito de los nombres en cuantos símbolos -en términos semióticos- es estrechar el vínculo de la comprensión epistemológica y ontológica del mundo creado con su principio (Fischer, 2001, p. 532). La necesidad de buscar la significación del nombre para llegar a su fundamento se asienta en el símbolo, que es una forma de develamiento de lo más desconocido. La Epístola I revela la dificultad de conocer a Dios del siguiente modo:

La tiniebla se torna inmanifiesta con la luz, y más aún con mucha luz; [...] el inconocimiento según Dios permanece escondido a los que tienen luz-ente y conocimiento de entes, y la tiniebla que la supera [a esa luz] no sólo es cubierta por toda luz sino que también oculta todo conocimiento. Y si alguien, tras ver a Dios, comprende lo que vio, no lo han visto a Él sino algo de las cosas de Él, existentes y conocidas; Él, en cambio, supraasentado por encima de inteligencia y esencia, por el hecho mismo de no ser conocido enteramente y de no ser, no sólo existe supraesencialmente sino también se conoce por encima de inteligencia. Y el in-conocimiento totalmente perfecto, según el mejor sentido, es conocimiento del Que está por encima de todo lo que se conoce (Ep., I, 1054a).

La divinidad se encuentra por encima de todo ente, de toda intelección y, por lo tanto, por encima de todo nombre. Sin embargo puede ser nombrado a partir de los aquellas denominaciones que aluden a entes; es conocido a través de todas las cosas, y, a la vez, por medio de ninguna. Al respecto, expresa Jeffrey Fischer (2001): "Por lo tanto, 'Dios es conocido en todas las cosas [comprendido como símbolo] y como distinto de todas las cosas [comprendido como resguardo o escudo]', este último sentido es claramente preferido por Dionisio a causa de su forma negativa" (p. 532; traducción propia) ${ }^{28}$. Dios es conocido

28 "Thus, 'God is known in all things [projection as symbol] and as distinct from all things [projection as shield]', the latter resulting in Dionysius' clear preference for the negative way." 
en la proyección de las cosas en cuanto símbolos; sin embargo, dado que es esencialmente distinto de todas ellas, aparece velado y resguardado por ellas.

Los símbolos tienen también la función de proteger lo sagrado, de iluminar ocultando, con el único y noble lenguaje que nos ha sido dado. Se despliega como un precioso manto de rica multiplicidad, cubriendo -si esto es posible- el espectro inabarcable de la divina penumbra.

\subsubsection{Los nombres en el contexto de los hápax}

LOS HÁPAX SON NEOLOGISMOS que refieren en Los nombres divinos a expresiones sobre la esencia y el accionar de Dios. Este decir de modo diferente es un nombrar extraño a lo cotidiano, a lo sabido y conocido, y por ello se mantiene de algún modo en las proximidades del silencio - del decir y no decir-, a la vez que en la posibilidad de acontecer en el interior del pensamiento del ser humano y también en su exterioridad, en la palabra nueva que nace de su boca. Nueva en cierto sentido, pues para los humanos se entiende perfectamente esta contorsión lingüística, este movimiento del lenguaje, que llega a ser vida renovada y anhelo de lo eterno.

Por revelarse incognoscible, es lógico que el autor utilice tantas locuciones nuevas, por el carácter inenarrable de Aquél. Lo inefable se contiene de algún modo en este lenguaje, que incluye una articulación diferente de la habitual, un acercamiento nunca directo sino circundante y al mismo tiempo abismalmente distante de la noción de la divinidad.

No solamente crea lenguaje, sino que también utiliza vocablos existentes,

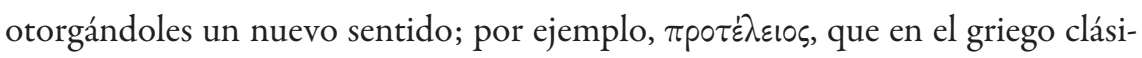
co significa 'preludio' o 'que precede a una ceremonia', pero que en Dionisio es 'preperfecto', perfecto por anticipado; o ouvoxıкós, que para Proclo, Simplicio y Damascio significa 'que concierne a o crea continuidad', y que en Dionisio es usado como 'contenedor', entre otros.

Los neologismos plenos son en su mayoría hápax, de los cuales se han registrado un total de 124 (Cavallero, 2004, pp. 131-146): aparecen por única vez en Dionisio y solo en Los nombres divinos. Son cualidades de Dios, o formas que dicen aspectos de lo que sería su esencia. Algunos de ellos utilizan la $\alpha$-privativa, denotando una negación, en cuanto que no es lo que las cosas creadas son, y se 
refieren a la imposibilidad intelectual del hombre de acceder a Dios. Por ejem-

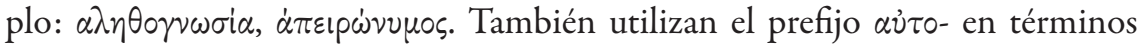

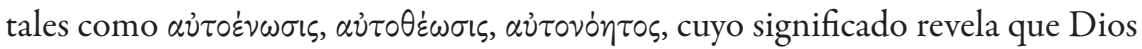
contiene todo lo existente; del mismo modo, aparece àpxý en relación con la

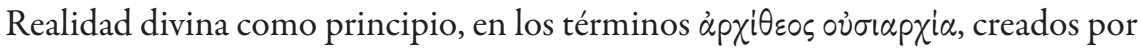
el teólogo. $\Upsilon \pi \dot{\varepsilon}$ - indica la idea de que Dios supera o excede todo, como en los

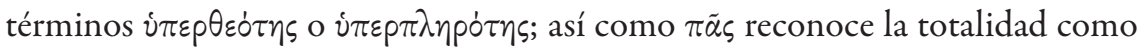
característica de lo divino, por ejemplo en $\pi \alpha v v o \eta t o ́ s$.

La novedad lexicográfica de Dionisio consiste en adaptar o modificar las palabras comunes a su intención de dar nombre a Dios y con ello alabarlo. En su amplio análisis filológico, Pablo Cavallero (2007) explicita en la introducción de Los nombres divinos:

Si pensamos que todo el tratado de Los nombres divinos se funda en el comentario a las denominaciones que las escrituras dan a Dios, la función "litúrgica" del tratado se muestra doble, por cuanto elogia a la Biblia misma como Palabra de Dios y elogia a Dios como La Palabra supraeminente. [...] El tratado canta alabanzas al Dios inefable, al Dios-Palabra mediante insuficientes palabras humanas que surgen de la humana plasmación de la Revelación divina, que son las Escrituras. El sentido litúrgico del tratado, que es predicación de la Palabra y oración de alabanza, es aún más claro cuando Dionisio concluye el capítulo X con la típica expresión Aừv (217: 4) (pp. 66-67).

De este modo, se puede valorar la particular denominación dionisiana como un reflejo de la necesidad de salir de los cánones normales del léxico, con el objeto de crear y transmitir expresiones y formas nuevas de persistir en el intento por alcanzar la realidad más alta que es dable pensar. El paradójico fin del Areopagita es elaborar un tratado acerca de cómo nombrar lo innombrable, esto es, "[...] tener que referirse a lo inexpresable mediante un lenguaje insuficiente que expresa la incapacidad de la inteligencia para captar aquello que solo puede captar la unión del éxtasis amoroso" (Cavallero, 2007, p. 69).

En esta concepción, el Principio se revela como una 'ausencia-presencia', preservando al pensamiento de caer en la noción de Dios como uno más de los seres del universo, aunque, en última instancia, la contemplación de la divinidad por el ser humano implica siempre un 'salir de sí mismo' (éxtasis), abandonando 
todo ser o no ser, en el desierto del silencio (Vega, 1999, p. 68), para que Dios se manifieste ${ }^{29}$.

\section{Consideraciones finales}

El Areopagita concibe un Universo necesitado de regresar a su fuente y fundamento inteligible. En este recorrido, los símbolos e imágenes del lenguaje hacen las veces de puente o apertura para el pensamiento humano, que se encuentra completamente limitado para acceder a las realidades superiores.

¿Pero cómo conciliar la absoluta trascendencia divina con los nombres? Lo cierto es que no puede haber para nosotros un conocimiento no simbólico de Dios. Los nombres se presentan como aquellas "luces teárquicas" ${ }^{30}$, teofanías de la Tearquía, aquello a través de lo cual Dios se muestra y que acoge una "semejanza desemejante" en la que el lenguaje permite en cierto modo delimitar lo inefable.

Del mismo modo, en general, todo ser es símbolo y, en cuanto tal, su función es interpretar lo inaccesible, anunciar el silencio divino, en un intento de unificación con Él. Esta búsqueda de lo supremo se manifiesta como eutonía o tensión hacia lo divino. En efecto, todo ser o símbolo no es Dios mismo, sino que lo oculta, dejándolo "detrás", inaccesible. Dionisio apunta que la oscuridad llega a ser invisible a causa de la luz, y más invisible es cuanto más luz se haga presente. En este sentido, la analogía se refiere al conocimiento humano como una luz que cuanto más pretenda aclarar la realidad divina, le resultará tanto más incognoscible e invisible (Ep., I, 1065a).

La luz es causa y contenido de toda visión, porque su presencia oculta la oscuridad, haciéndola invisible. $\mathrm{Al}$ aprehender el símbolo, como manifestación visible -porque es un ser- se comprende que este no es Dios mismo. Ocultar a

$29 \mathrm{Al}$ respecto, dice Bezerra (2007): "podemos afirmar que el pensamiento dionisiano constituye un marco diferenciador en la tradición cristiana, dado que se atreve a renunciar a la objetividad de un fundamento absoluto para asumir el vacío de un Dios que es retraimiento y supresión" (pp. 141142; traducción propia). ["podemos afirmar que o pensamento dionisiano é um marco diferenciador na tradição cristä, dado que ousa renunciar a objetividade de un fundamento absoluto para assumir o vazio de um Deus que é retraimento e supressão"].

30 Teárquico se refiere aquí a lo divino. 
Dios en este sentido es revelarlo como más allá del ser y del pensamiento: "saber algo es, ipso facto, no conocer a Dios" (Perl, 2007, p. 104; traducción propia) $)^{31}$.

De este modo, no ver es ver oscuridad. Dejar la oscuridad invisible, ocultarla, es así descubrirla en cuanto oscuridad, único modo en que puede ser revelada ante el hombre. Paradójicamente, solo permaneciendo oculto en los símbolos puede Dios revelarse: los nombres divinos nos elevan a través de un lenguaje de alabanza y nos mantienen en tensión hacia lo Absoluto.

\section{Referencias}

Andereggen, I. E. M. (1989). La metafísica de Santo Tomás en la Exposición sobre el De divinis nominibus de Dionisio Areopagita. Buenos Aires: Educa.

de Andía, Y. (1996). Henosis. L'union à Dieu chez Denys l'Aréopagite. Leiden: Brill.

Beierwaltes, W. (1997) Dionysius Areopagites: ein christlicher Proklos? En: Kobusch, T. \& Mojsisch, B., Platon in der abendländischen Geistesgeschichte (pp. 71-100). Darmstadt: Wissench Buchgesch.

Bezerra, C. C. (2007) Apóphasis y kénosis en Dionisio Areopagita. Teorema, 26(1), 117-130.

Bezerra, C. C. (2009). Dionisio Pseudo-Areopagita: Mistica e Neoplatonismo. São Paulo: Paulus.

Cavallero, P. A. (2004). Las ideas-clave de Los nombres divinos de Pseudo Dionisio según el uso léxico. Temas Medievales, 12, 131-146.

Cavallero, P. (2007) Introducción. En: Dionisio Areopagita, Los nombres divinos ( $1^{\text {a }}$ ed., trad. P. A. Cavallero). G. Ritacco (Ed.). Buenos Aires: Losada.

Corsini, E. (1962). Il trattato De divinis nominibus dello Pseudo-Dionigi e icommenti neoplatonici al Parmenide. Torino: Giappichelli.

van den Daele, A. (1941). Indices Pseudo-Dionysiani. Louvain: Les Belles Lettres. Dionisio Areopagita (2007). Los nombres divinos $[D N]$. (1 ${ }^{\text {a }}$ ed., trad. P. A. Cavallero). G. Ritacco (Ed.). Buenos Aires: Losada.

31 "To know any thing is, ipso facto, not to know God." 
Dionisio Areopagita. (2008). La jerarquía celestial. La jerarquía eclesiástica. La teología mistica. Epistolas. (Trad. P. A. Cavallero). Buenos Aires: Losada.

Fernández Fernández, Á. (2011) La teúrgia de los oráculos caldeos. Cuestiones de léxico y de contexto histórico. Granada: Editorial de la Universidad de Granada.

Fischer, J. (2001). The Theology of Dis/similarity: Negation in Pseudo-Dionysius. The Journal of Religion, 81 (4), 529-548. DOI: 10.1086/490935

Janowitz, N. (1991). Theories of Divine Names in Origen and Pseudo-Dionysius. History of Religions, 30(4), 359-372. DOI: 10.1086/463246

Luck, G. (1989). Theurgy and forms of worship in neoplatonism. En: Neuser, J. (ed.), Religion, science and magic in concert and in conflict (pp. 185-228). New York: Oxford University.

Molina Ayala, J. (2010). Teúrgia: camino de Jámblico a lo inefable. Diánoia, 55(65), 125-149.

Nieva, J. M. (2002). Jerarquización y divinización del hombre. Universitas Philosophica, 19(38), 139-149.

Pantelia, M. (Dir.) (2011). The Online Liddell-Scott-Jones Greek-English Lexicon (LSJ). Consultado el 24 de mayo de 2019, en http://stephanus.tlg.uci.edu/ $1 \mathrm{jj} / \#$ eid $=325$

Peirce, C. (1932). Collected Papers of Charles Sanders Peirce: Principles of Philosophy and Elements of Logic, vols. I-II, Hartshorne, C. \& Weiss, P. (eds). Cambridge: Harvard University Press.

Perl, E. D. (2007). Theophany. The Neoplatonic Philosophy of Dionysius the Areopagite. New York: New York Press.

Rolt, E. (2000). Dionysius the Areopagite: On the Divine Names and the Mystical Theology. London: Christian Classics Ethereal Library.

Rorem, P. (1984). Biblical and Liturgical Symbols within the Pseudo-Dionysian Synthesis. Studies and Texts (vol. 71). Toronto: Pontifical Institute of Mediaeval Studies.

Saffrey, H. D. (1990). Nouveaux liens objectifs entre le Pseudo-Denys et Proclus. En: Saffrey, H. D, Recherches sur le Néoplatonisme, Histoire des doctrines de l'Antiquité classique 14 (pp. 227-248). Paris: Vrin.

Saffrey, H. D., \& Westerink, L. G. (1968). Proclus : Théologie platonicienne (vol. 1). Paris: Les Belles Letres. 
Stang, C. (2010). La herencia cristiana de la teúrgia pagana (Trad. C. Blanco). En: M. López Salvá (Ed.), De cara al Más Allá: Conflicto, convivencia y asimilación de modelos paganos en el cristianismo antiguo (pp. 185-202). Madrid: Pórtico.

Stiglmayr, J. (1895). Das Aufkommen der pseudo-dionysischen Schriften und ibr Eindringen in die christliche Literatur bis zum Laterankonzil. Lausgruber: Feldkirch.

Vanneste, J. (1958). Le mystère de Dieu, essai sur la structure rationelle de la doctrine mystique du Pseudo-Denys l'Aréopagite. Bruselas: Desclée de Brouwer.

Vega, A. (1999). La huella del desierto en el Maestro Eckart. Revista de Filosofía, 24-25, 49-72.

Vogel, C. (1993). Platonism and Christianity: A Mere Antagonism or a Profound Common Ground? (Trad. E. Peroli). Milano: Vita e Pensiero.

Wear, S. K., \& Dillon, J. (2007). Dionisyus and the Neoplatonist Tradition. Aldershot: Ashgate. DOI: 10.4324/9781351159845 